\title{
Influencing Factors in Autotransplantation of Teeth with Open Apex: A Review of the Literature
}

\author{
María P. Pecci Lloret ${ }^{1}$, Elena Pina Martínez ${ }^{1}$, Francisco J. Rodríguez Lozano ${ }^{1}{ }^{1}$, Miguel R. Pecci Lloret ${ }^{1}$, \\ Julia Guerrero Gironés ${ }^{1, *}$, Francesco Riccitiello ${ }^{2}$ and Gianrico Spagnuolo ${ }^{2,3}$ D \\ 1 Special Care in Dentistry and Gerodontology Unit, Hospital Morales Meseguer, Faculty of Medicine, \\ University of Murcia, 30100 Murcia, Spain; mariapilar.pecci@um.es (M.P.P.L.); hepina83@gmail.com (E.P.M.); \\ fcojavier@um.es (F.J.R.L.); miguelramon.pecci@um.es (M.R.P.L.) \\ 2 Department of Neurosciences, Reproductive and Odontostomalogical Sciences, University of Naples \\ “Federico II", 80131 Napoli, Italy; riccitie@unina.it (F.R.); gspagnuo@unina.it (G.S.) \\ 3 Institute of Dentistry, I. M. Sechenov First Moscow State Medical University, 119146 Moscow, Russia \\ * Correspondence: julia.guerrero@um.es; Tel.: +34-8-6888-9518
}

\section{check for} updates

Citation: Pecci Lloret, M.P.; Martínez, E.P.; Rodríguez Lozano, F.J.;

Pecci Lloret, M.R.; Guerrero Gironés,

J.; Riccitiello, F.; Spagnuolo, G.

Influencing Factors in

Autotransplantation of Teeth with

Open Apex: A Review of the

Literature. Appl. Sci. 2021, 11, 4037.

https://doi.org/10.3390/app11094037

Academic Editor: Fabio Renato

Manzolli Leite

Received: 20 March 2021

Accepted: 26 April 2021

Published: 29 April 2021

Publisher's Note: MDPI stays neutral with regard to jurisdictional claims in published maps and institutional affiliations.

Copyright: (c) 2021 by the authors. Licensee MDPI, Basel, Switzerland. This article is an open access article distributed under the terms and conditions of the Creative Commons Attribution (CC BY) license (https:// creativecommons.org/licenses/by/ $4.0 /)$.

\begin{abstract}
Dental autotransplantation is the process by which a tooth located in its natural socket is extracted and relocated to another socket in which the tooth is missing or has been extracted due to various reasons such as trauma, extensive caries or periapical pathology, among other reasons. This proposed technique offers a more conservative alternative for patients in comparison with prosthetic or implant techniques, especially in young patients where implants are contraindicated until their maxillary bone system's growth ends. Thus, the objective of this review was to present a qualitative synthesis of the risk factors that influence the results of open apex dental autotransplantation in humans. After confirming that there are various factors that influence dental autotransplantation, it was concluded that the extra-alveolar time of the donor tooth and the periodontal damage of the root of the donor tooth are the factors of greatest interest in the literature, both closely linked to the use of $3 \mathrm{D}$ replication of the transplanted tooth.
\end{abstract}

Keywords: tooth autotransplantation; open apex; influencing factors; immature apex; young patients

\section{Introduction}

When a tooth loss occurs, it is essential to replace it to prevent functional, aesthetic and/or psychological problems. Currently, the most common treatments when a dental absence is faced are removable prostheses, implants or orthodontics. However, there is another less known option called dental autotransplantation, a promising alternative, especially in young patients, where the treatments mentioned above may not be suitable or cannot be performed [1-7]. This technique has various advantages compared with conventional methods, such as the use of autologous tissue to preserve the periodontal ligament, the preservation of the masticatory function and the favorable aesthetic results [1-4].

Dental autotransplantation is defined as the transplantation of an impacted or erupted tooth to another site, extraction socket or surgically prepared socket in the same individual $[1,2,8]$. This technique is used to replace a tooth that has to be extracted either because it has been lost due to trauma, its restoration is impossible, endodontic treatment has failed or it has been fractured [1,2,9]. A success rate of $89.68 \%$ (any signs of pathology or need for additional procedures) and a survival rate of $98 \%$ (persistence of the transplanted tooth, with the need for additional procedures) have been calculated in open apex autotransplantation [10] and 80\% success and 95\% survival in the mature apex [11].

The extracted tooth's socket is used to hold the transplanted tooth, making the necessary modifications to make it fit perfectly. If the tooth's absence is maintained over an 
extended period of time, a new socket may need to be made using drilling techniques similar to those used in implantology $[1,2,9,12,13]$.

Dental autotransplantation presents a series of advantages. One of the most important is that it can be performed in growing patients, unlike current implantology techniques $[4,5,14,15]$. In addition, it also allows one to maintain a vital periodontium, allowing continuous growth, the preservation of the volume of the alveolar bone, better conservation of the interdental papilla [5] and the possibility of dental movement through orthodontic forces [2,5,16-18]. Likewise, it has been proven that the longevity and prognosis of autotransplanted teeth are comparable with those of dental implants [9].

On the other hand, a series of complications can occur during or after performing this technique, such as iatrogenesis or errors regarding case selection, which can cause the patient to present ankylosis, root resorption, pulp necrosis or loss of the periodontal ligament. These complications can eventually lead to tooth loss [1,19-21]. When root formation is incomplete, it is more difficult for these complications to occur, since the pulp tissue has greater regeneration potential. However, in teeth in which root formation is complete, complications may be more likely to occur. For this reason, it has been suggested that root canal treatment should be performed 2 weeks after the autotransplant has been performed [1,19-21].

Considering the novelty of this technique in daily dental practice, its promising success rates and its potential complications, it seemed convenient to carry out an updated review on the factors influencing the results of open apex dental autotransplantation in humans.

\section{Materials and Methods}

\subsection{Eligibility Criteria}

- Full access to the text;

- Text published in English;

- Studies conducted in humans;

- Published in the last 5 years, from 2015 to 2020;

- Young patients with open apex autotransplanted teeth.

\subsection{Search Strategy}

The search, study selection and data extraction process was carried out by 2 different researchers (E.P. and M.P.P.L.). In the event of any discrepancy between them, a third investigator was consulted (J.G.G.).

An electronic search was performed in the Medline database in February 2020 and last updated on December 2020. The search strategy was designed considering previous studies in the field and their most cited keywords. Accordingly, the following terms were combined for each database: " tooth autotransplantation", "incomplete root", "open apex", "young patients" and "children patients". The Boolean operator "AND" was used to combine the terms and design the search strategy, as shown in Table 1.

Table 1. Search strategy and database.

\begin{tabular}{ccc}
\hline Database & Search Strategy & Findings \\
\hline Medline & (Tooth autotransplantation) AND (incomplete root) & 28 \\
& (Tooth autotransplantation) AND (open apex) & 12 \\
& (Tooth autotransplantation) and (children patients) & 148 \\
& (Tooth autotransplantation) AND (young patients) & 100 \\
\hline
\end{tabular}

\subsection{Study Selection}

The studies identified using the search strategy were exported from each database into Mendeley reference manager software (Elsevier, Amsterdam, Netherlands). An initial screening of the recorded titles and abstracts was performed following the inclusion and 
exclusion criteria. Studies which met the criteria were further assessed for eligibility by full-text screening.

\subsection{Data Extraction}

Data extracted from the selected studies were divided into variables for study characteristics, methodology and results/outcomes. The variables recorded for study characteristics were authors and year of publication. Methodological variables included the number of teeth, apex formation, dental stabilization, and 3D replica. Result variables included the duration of the study and the survival rate.

\section{Results}

Search Results and Study Selection

The search identified 288 preliminary results in Medline. Of these, 259 were removed (196 were not from the last 5 years, 1 was not written in English, 11 were non-human studies, 15 were discarded by title, 5 were discarded by abstract and 9 were not available). The resulting 29 articles were assessed by full-text screening and all of them were considered suitable for qualitative synthesis (Figure 1).

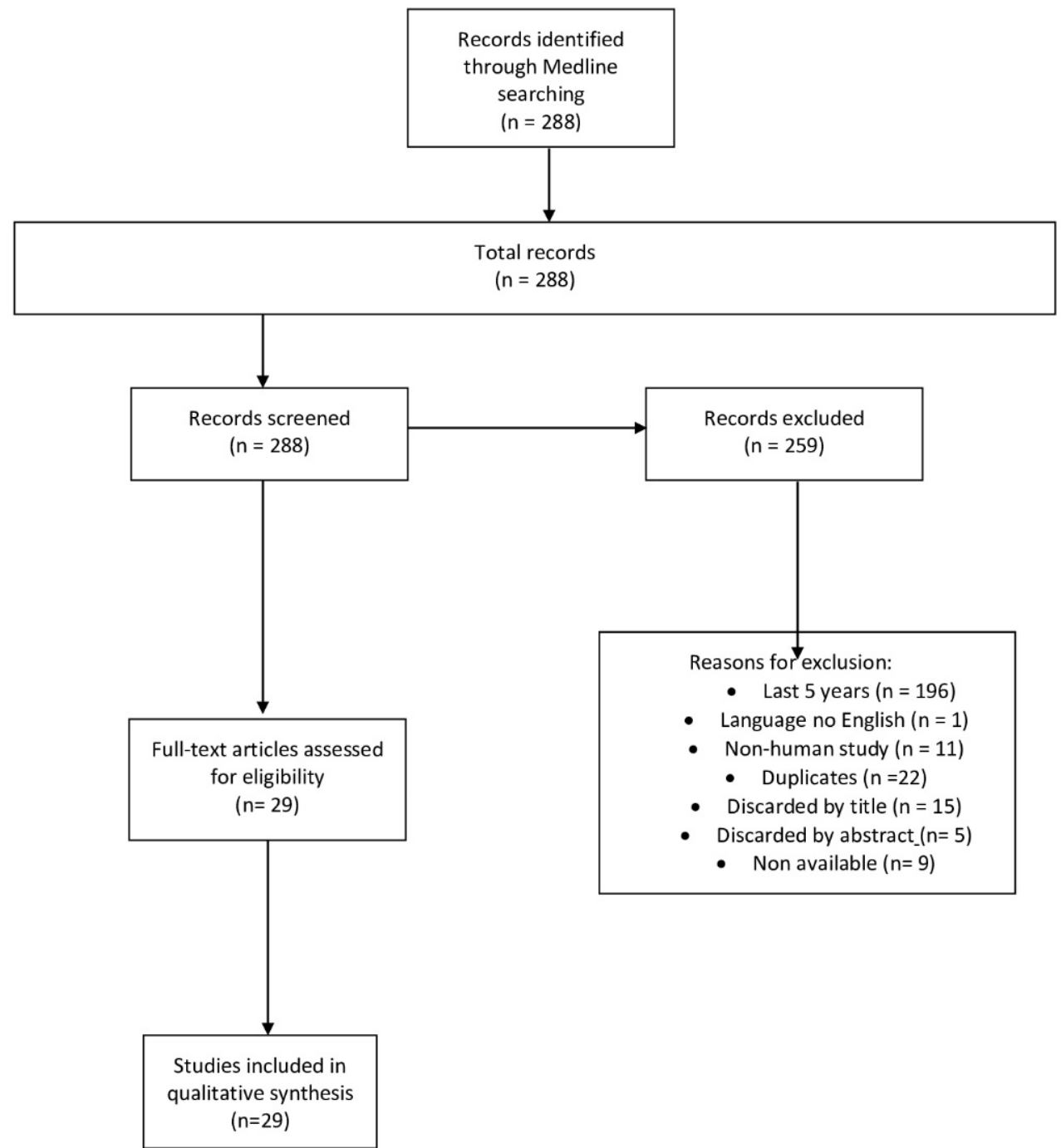

Figure 1. Flowchart representing study inclusion. 


\section{Review}

Both studies assessing children and young adolescents were considered in this review, since the age range for the presentation of teeth with a physiological open apex may extend to 21 years of age. According to the literature consulted, numerous factors influence the success of dental autotransplantation in incompletely developed teeth. They are detailed below and categorized according to the donated tooth, the recipient socket or the treatment technique.

When selecting the donated tooth to be transplanted into another socket, the following should be considered:

- Stage of tooth root formation: It is most optimal when between two-thirds and threequarters of the root have formed [22]. Some authors did not find significant differences if the tooth presented a minor root formation [23]. Some authors indicated that the diameter of the root canal in a tooth with a wide open apex (1-2 $\mathrm{mm}$ ) decreases the risk of pulp necrosis, since the revascularization of the pulp is greater and implies a new supply of blood and nervous fibers that achieve the vitality of the tooth $[17,24]$. If the formation of the tooth root is not completed, it will do so in its new location [25]. In addition, the preservation of the alveolar bone and revascularization of the pulp may be achieved [25], avoiding root canal treatment and its possible complications due to its difficulty in this kind of tooth [26].

- Type of tooth [17]: According to the literature, the premolar is the tooth most used as a donor in cases of open apex $[27,28]$. It has been described that this may be because premolars are the teeth most commonly extracted in orthodontic treatments $[22,27,29,30]$. Others report that transplants of third molars, impacted canines and supernumerary teeth are also common, and that there is no significant difference if the donor's tooth comes from the maxilla or the mandible [29,31-33]. In his study, Tang considered an optimal root as one that is morphologically conical, smooth and simple, considering teeth with multiple roots and a rough surface to be more complicated [29].

- Eruption state [17]: Teeth can be categorized as not erupted, partially erupted or fully erupted [17]. Tang, in his study, included erupted or embedded teeth that were not previously functional [29], with those that had erupted being easier to remove without damaging the periodontal ligament.

- The state of the periodontal ligament [17]: Kafourou et al. [17] described how the state of the periodontal ligament is key to the success of dental transplantation and that excessive trauma has a negative influence on the treatment's prognosis [17]. It of vital importance that the soft tissue surrounding the periodontal ligament-that is, the cells that make up Hertwig's root sheath-is not injured during the extraction of the donor's tooth [26], as well as the apical papilla stem cells (SCAPs), which are fundamental for the root development of immature teeth [34]. The extraction must be atraumatic and prevent damage to the tissues surrounding the tooth $[25,27,29]$, in order to increase the success and survival rate of the autotransplant [23]. Additionally, Gilijamse et al. [35] assured us that an intact periodontal ligament around the tooth facilitates its growth and adaptation to the alveolar bone, and also explained that to avoid damage to this tissue, the size of the new alveolus must be greater than that of the donor tooth. This guarantees the preservation of the tissue and thus reduces the risk of ankylosis and external root resorption [35]. However, he also described how teeth transplanted into the socket without any modification have a higher survival rate [35]. Tsukiboshi qualified this factor as the most important for successful transplantation [36]. Altogether, it is essential that the periodontal ligament covering the tooth is not damaged to avoid ankylosis and root resorption, and induce the formation of bone for the healing of the area [36], as well as the Hertwig sheath, in order to continue the development of the root of the transplanted tooth [36].

The factors that need to be considered in order to categorize the receptor alveolus as optimal are the following: 
- Location: Regarding the maxillary or mandibular location of the receptor alveolus, better results are described in the maxilla [28], although little significant differences are mentioned [25]. Nevertheless, authors describe how autotransplants in the anterior maxilla require greater aesthetic results [28].

- Volume of alveolar bone and quality: It is stated that if the bone is deficient both in quantity or quality, it has a negative influence on the success of the transplant, since the surgery is hindered and the aesthetic result may be compromised. For this reason, an adequate thickness of the buccal and lingual cortical bone of the area where the tooth will be transplanted is required [17]. In fact, Gilijamse et al. [35] reported that one of the primary factors for the transplant's success is that the walls of the recipient socket must have acceptable dimensions to guarantee the stability of the donor tooth. Additionally, if the extracted tooth presents ankylosis or infection in the recipient socket, it could influence the new tooth's adaptation to the socket. [17]. Early tooth loss during the patient's growth period and the absence of replacement by dental autotransplantation has a negative influence on the quality of the residual bone, which will be needed for the placement of an implant after the growth period has ended [17]. This results in the need for previous bone graft procedures $[17,26]$.

- Tissue damage during the procedure: Some authors stated that the affected tooth must be extracted carefully, trying to contact the ligament as little as possible to avoid ankylosis and other complications [5,27,35]. Verweij et al. [27] also highlighted the importance of minimizing the iatrogenic damage caused by the excessive attempts to fit the replica in the alveolus.

The following factors influence the technique:

- Use of a 3D replica [30]: that has been manufactured from a previous CBCT [27] and that facilitates the dental autotransplantation process $[16,27,28,37,38]$, reducing the manipulation and extra-alveolar time of the transplanted tooth [26,39]. By using the replica of the donor's tooth, the extra-alveolar time is minimized to less than 1 minute [27], even seconds [40]. At the same time, as an alternative to this individualized replica of the patient's tooth, a pre-designed surgical template or guide of the type of donor tooth in question could be used, which can be sterilized and reused, but this entails a size discrepancy between the template and the donor tooth $[27,38]$. EzEldden et al. [30] made use of this surgical guide to favor the position of the donor tooth and confirmed that as a result of the use of the replica, the time of the surgery itself was reduced, going from 40 to $90 \mathrm{~min}$ in surgeries without replication and up to 30 to $45 \mathrm{~min}$ in surgeries where this replica was used. Furthermore, EzEldden pointed out that everything manipulated using this replica is not performed on the donor's tooth, so it helps to keep its periodontal ligament intact, avoiding future root resorption, pulp necrosis or other possible complications [30].

- Stabilization of the donor tooth and its duration [17]: It is important to stabilize the donor tooth to prevent mobility, since a lack of retention increases trauma and instability while healing occurs [41]. There is controversy about the material to be used and the time to splint the donor tooth. Sutures cause less risk of ankylosis compared with wire, while the probability of failure will be higher [27,29]. Verweij et al., Gilijamse et al. and Strbac et al. $[23,25,27,35]$ used sutures to stabilize the tooth in an interocclusal position, as did Jakobsen et al. [22], who also used sutures and kept them for a week. Gonzalez-Ocasio et al. used orthodontic wires with a composite to splint the transplanted teeth to the adjacent teeth for a month [42], and other authors such as Mejía Cardona et al. [26] used a combination of sutures and splints and kept the tooth in infraocclusion for 6 weeks or 3 weeks [33]. Meanwhile, Tang et al. [27] indicated that in a series of treated cases, no significant differences were found in terms of the stabilization method.

- Extra-alveolar time of the donor tooth and its storage [23]: Some authors state that it is vital to minimize the extra-alveolar time of the donor tooth as much as possible to preserve the periodontal ligament and maintain Hertwig's epithelial sheath [43], and 
to reduce complications $[5,23,27]$. Strbac et al. [25] suggested that during this time, the tooth must be preserved in a saline solution in order to not to interfere with the possibility of pulp revascularization [23]. EzEldeen et al. [30] highlighted that with the use of a replica, the donor tooth's extra-alveolar time is reduced to less than 1 minute, whereas the extra-alveolar time of the donor tooth can be around $10 \mathrm{~min}$ in other circumstances.

- Operator/surgeon's experience: Jakobsen et al. [22], in their study, concluded that there are no significant differences in terms of the operator's experience, nor in the occurrence of adverse effects. Similarly, Stange et al. [28], in their study, could not validate this factor, since the same operator performed all operations, but they noted that, as in all dental procedures, experience is a must. Meanwhile, Juslin et al. [39] confirmed that surgeon experience increased the survival rate of the dental autotransplantation in $17 \%$ of cases.

- Need for endodontic treatment [23]: In the case of an open apex, an immediate root canal treatment should not be performed, so that a follow-up can be carried out and the root may finish forming without showing signs or symptoms of infection [2,31]. Root canal treatment is needed only when there are radiological signs of resorption or periapical pathology [31]. If there is positive pulp sensitivity, it will be classified as success, while if there is negative pulp sensitivity, it will be classified as survival [10]. Moreover, $96 \%$ pulp healing success without the need for endodontics has been observed in autotransplants with open apex, compared with $15 \%$ in mature teeth [44]. Verweij et al. reflected that if root canal treatment is necessary, it should be performed prior to transplantation or 15 days after it [23]. Kafourou et al. and Tsukiboshi et al. [17,36] considered performing a root canal treatment when necessary, 15 days after transplantation. Furthermore, Kafourou et al. [17] added that teeth treated endodontically after dental autotransplantation have a favorable prognosis.

- Treatment follow-up: Tsukiboshi et al. [36] suggested a follow-up consisting of a monthly X-ray for the first 3 months to verify that there is no root resorption or pulp necrosis. If there is no evidence of this, further follow-up visits are scheduled after 6 months, 2 years and 3 years [36]. The follow-up schedule that Tang et al. [29] described is as follows: 1 week, 2 weeks, 4 weeks, 2 months, 4 months, 6 months, 1 year, and 2 years. In addition, in open apex autotransplantation, it is important to have a radiological sequence taken in the follow-up sessions, where the continuous development of the root of a transplanted tooth with open apex can be ensured [30].

\section{Conclusions}

Dental transplantation is described as an attractive technique for the operator, which must be consensual through a multidisciplinary approach.

It has been found that the use of a replica of the tooth for dental transplantation is essential, since it obtained higher success and survival rates when compared with those that did not use a replica.

It was stated that the most critical risk factors in dental transplantation are the reduction of the extra-alveolar time of the donor tooth and the preservation of the periodontal ligament that surrounds the donor tooth. Both have the essential objective of not damaging the cells of the periodontal ligament that make up the development of the tooth root, as well as the revascularization of its pulp, these being factors closely related to the use of the replica.

Author Contributions: Conceptualization, G.S. and F.R.; methodology, E.P.M.; formal analysis, E.P.M., M.P.P.L. and J.G.G.; investigation, F.J.R.L.; data curation, M.R.P.L.; writing-original draft preparation, M.P.P.L. and M.R.P.L.; writing—review and editing, F.R. and G.S.; visualization, J.G.G.; supervision, M.R.P.L. All authors have read and agreed to the published version of the manuscript.

Funding: This research received no external funding.

Institutional Review Board Statement: Not applicable. 
Informed Consent Statement: Not applicable.

Data Availability Statement: The data presented in this study are available on request from the corresponding author.

Conflicts of Interest: The authors declare no conflict of interest.

\section{References}

1. Chung, W.-C.; Tu, Y.-K.; Lin, Y.-H.; Lu, H.-K. Outcomes of autotransplanted teeth with complete root formation: A systematic review and meta-analysis. J. Clin. Periodontol. 2014, 41, 412-423. [CrossRef] [PubMed]

2. Murtadha, L.; Kwok, J. Do Autotransplanted Teeth Require Elective Root Canal Therapy? A Long-Term Follow-Up Case Series. J. Oral Maxillofac. Surg. 2017, 75, 1817-1826. [CrossRef] [PubMed]

3. Schwartz-Arad, D.; Bichacho, N. Effect of age on single implant submersion rate in the central maxillary incisor region: A longterm retrospective study. Clin. Implant Dent. Relat. Res. 2015, 17, 509-514. [CrossRef]

4. Daftary, F.; Mahallati, R.; Bahat, O.; Sullivan, R.M. Lifelong craniofacial growth and the implications for osseointegrated implants. Int. J. Oral Maxillofac. Implant. 2013, 28, 163-169. [CrossRef]

5. Ong, D.; Itskovich, Y.; Dance, G. Autotransplantation: A viable treatment option for adolescent patients with significantly compromised teeth. Aust. Dent. J. 2016, 61, 396-407. [CrossRef] [PubMed]

6. Schaaf, H.; Kerkmann, H.; Pitka, F.; Bock, N.C.; Attia, S. Replantation of a displaced incisor in a boy with a cleft lip and alveolus: A case report. J. Med. Case Rep. 2016, 10, 1-5. [CrossRef] [PubMed]

7. Parvini, P.; Obreja, K.; Trimpou, G.; Mahmud, S.; Sader, R. Autotransplantation of teeth. Int. J. Esthet. Dent. $2018,13,274-282$.

8. Candeiro, G.T.; Alencar-Júnior, E.A.; Scarparo, H.C.; Furtado-Júnior, J.H.; Gavini, G.; Caldeira, C.L. Eight-year follow-up of autogenous tooth transplantation involving multidisciplinary treatment. J. Oral Sci. 2015, 57, 273-276. [CrossRef]

9. Tsukiboshi, M. Autotransplantation of teeth: Requirements for predictable success. Dent. Traumatol. 2002, 18, 157-180. [CrossRef]

10. Atala-Acevedo, C.; Abarca, J.; Martínez-Zapata, M.J.; Díaz, J.; Olate, S.; Zaror, C. Success rate of autotransplantation of teeth with an open Apex: Systematic Review and Meta-Analysis. J. Oral Maxillofac. Surg. 2017, 75, 35-50. [CrossRef]

11. Boschini, L.; Melillo, M.; Berton, F. Long term survival of mature autotransplanted teeth: A retrospective single center analysis. J. Dent. 2020, 98, 103371. [CrossRef] [PubMed]

12. Jaiswara, C.; Srivastava, V.K.; Dhiman, N. Autotransplantation of a strange positioned impacted central incisor in a surgically prepared socket: A miracle esthetic concept. Int. J. Clin. Pediatr. Dent. 2016, 9, 269-272. [CrossRef] [PubMed]

13. Lucas-Taulé, E.; Llaquet, M.; Muñoz-Peñalver, J.; Somoza, J.; Satorres-Nieto, M.; Hernández-Alfaro, F. Fully Guided Tooth Autotransplantation Using a Multidrilling Axis Surgical Stent: Proof of Concept. J. Endod. 2020, 46, 1515-1521. [CrossRef] [PubMed]

14. Szemraj-Folmer, A.; Kuc-Michalska, M.; Plakwicz, P. Patient with asymmetric multiple hypodontia treated with autotransplantation of 2 premolars. Am. J. Orthod. Dentofac. Orthop. 2019, 155, 127-134. [CrossRef]

15. Ferreira, M.M.; Ferreira, H.M.; Botelho, F.; Carrilho, E. Autotransplantation combined with orthodontic treatment: A case involving the maxillary central incisors with root resorption after traumatic injury. Restor. Dent. Endod. 2015, 40, 236-240. [CrossRef]

16. Cousley, R.R.J.; Gibbons, A.; Nayler, J. A 3D printed surgical analogue to reduce donor tooth trauma during autotransplantation. J. Orthod. 2017, 44, 287-293. [CrossRef]

17. Kafourou, V.; Tong, H.J.; Day, P.; Houghton, N.; Spencer, R.J.; Duggal, M. Outcomes and prognostic factors that influence the success of tooth autotransplantation in children and adolescents. Dent. Traumatol. 2017, 33, 393-399. [CrossRef]

18. Kokai, S.; Kanno, Z.; Koike, S.; Uesugi, S.; Takahashi, Y.; Ono, T.; Soma, K. Retrospective study of 100 autotransplanted teeth with complete root formation and subsequent orthodontic treatment. Am. J. Orthod. Dentofac. Orthop. 2015, 148, 982-989. [CrossRef]

19. Bae, J.-H.; Choi, Y.-H.; Cho, B.-H.; Kim, Y.-K.; Kim, S.-G. Autotransplantation of teeth with complete root formation: A case series. J. Endod. 2010, 36, 1422-1426. [CrossRef]

20. Almpani, K.; Papageorgiou, S.N.; Papadopoulos, M.A. Autotransplantation of teeth in humans: A systematic review and meta-analysis. Clin. Oral Investig. 2015, 19, 1157-1179. [CrossRef]

21. Rohof, E.C.M.; Kerdijk, W.; Jansma, J.; Livas, C.; Ren, Y. Autotransplantation of teeth with incomplete root formation: A systematic review and meta-analysis. Clin. Oral Investig. 2018, 22, 1613-1624. [CrossRef]

22. Jakobsen, C.; Stokbro, K.; Kier-Swiatecka, E.; Ingerslev, J.; Thorn, J.J. Autotransplantation of premolars: Does surgeon experience matter? Int. J. Oral Maxillofac. Surg. 2018, 47, 1604-1608. [CrossRef] [PubMed]

23. Verweij, J.P.; Toxopeus, E.E.; Fiocco, M.; Mensink, G.; van Merkesteyn, J.P. Success and survival of autotransplanted premolars and molars during short-term clinical follow-up. J. Clin. Periodontol. 2016, 43, 167-172. [CrossRef] [PubMed]

24. van Westerveld, K.J.H.; Verweij, J.P.; Fiocco, M.; Mensink, G.; van Merkesteyn, J.P.R. Root elongation after autotransplantation in 58 transplanted remolars: The dadiographic width of the apex as a predictor. J. Oral Maxillofac. Surg. 2019, 77, 1351-1357. [CrossRef] [PubMed]

25. Strbac, G.D.; Giannis, K.; Mittlböck, M.; Fuerst, G.; Zechner, W.; Stavropoulos, A.; Ulm, C. Survival rate of autotransplanted teeth after 5 years-A retrospective cohort study. J. Cranio-Maxillofac. Surg. 2017, 45, 1143-1149. [CrossRef] 
26. Mejía-Cardona, J.L.; Marcano-Caldera, M.; Vera, J.; Sigurdsson, A. Autotransplantation of a premolar with incipient root development, an 18-Year Follow-Up. Eur. Endod. J. 2017, 2, 1-5. [CrossRef] [PubMed]

27. Verweij, J.P.; Moin, D.A.; Mensink, G.; Nijkamp, P.; Wismeijer, D.; van Merkesteyn, J.P. Autotransplantation of premolars with a 3-dimensional printed titanium replica of the donor tooth functioning as a surgical guide: Proof of concept. J. Oral Maxillofac. Surg. 2016, 74, 1114-1119. [CrossRef]

28. Stange, K.M.; Lindsten, R.; Bjerklin, K. Autotransplantation of premolars to the maxillary incisor region: A long-term follow-up of 12-22 years. Eur. J. Orthod. 2016, 38, 508-515. [CrossRef]

29. Tang, H.; Shen, Z.; Hou, M.; Wu, L. Autotransplantation of mature and immature third molars in 23 Chinese patients: A clinical and radiological follow-up study. BMC Oral Health 2017, 17, 163. [CrossRef]

30. EzEldeen, M.; Wyatt, J.; Al-Rimawi, A.; Coucke, W.; Shaheen, E.; Lambrichts, I.; Willems, G.; Politis, C.; Jacobs, R. Use of CBCT guidance for tooth autotransplantation in children. J. Dent. Res. 2019, 98, 406-413. [CrossRef]

31. Abela, S.; Murtadha, L.; Bister, D.; Andiappan, M.; Kwok, J. Survival probability of dental autotransplantation of 366 teeth over 34 years within a hospital setting in the United Kingdom. Eur. J. Orthod. 2019, 41, 551-556. [CrossRef] [PubMed]

32. Grisar, K.; Nys, M.; The, V.; Vrielinck, L.; Schepers, S.; Jacobs, R.; Politis, C. Long-term outcome of autogenously transplanted maxillary canines. Clin. Exp. Dent. Res. 2019, 5, 67-75. [CrossRef]

33. Tschammler, C.; Angermair, J.; Heiligensetzer, M.; Linsenmann, R.; Huth, K.C.; Nolte, D. Primary canine auto-transplantation: A new surgical technique. Oral Surg. Oral Med. Oral Pathol. Oral Radiol. 2015, 119, 158-169. [CrossRef] [PubMed]

34. Palma, P.J.; Martins, J.; Diogo, P.; Sequeira, D.; Ramos, J.C.; Diogenes, A.; Santos, J.M. Does apical papilla survive and develop in apical periodontitis presence after regenerative endodontic procedures? Appl. Sci. 2019, 9, 3942. [CrossRef]

35. Gilijamse, M.; Baart, J.A.; Wolff, J.; Sándor, G.K.; Forouzanfar, T. Tooth autotransplantation in the anterior maxilla and mandible: Retrospective results in young patients. Oral Surg. Oral Med. Oral Pathol. Oral Radiol. 2016, 122, e187-e192. [CrossRef]

36. Tsukiboshi, M.; Yamauchi, N.; Tsukiboshi, Y. Long-term outcomes of autotransplantation of teeth: A case series. Dent. Traumatol. 2019, 35, 358-367. [CrossRef]

37. Erdem, N.F.; Gümüsser, Z. Retrospective evaluation of immediate impacted third molars autotransplantation after extractions of mandibular first and/or second molars with chronic periapical lesions. J. Oral Maxillofac. Surg. 2021, 79, 37-48. [CrossRef]

38. Strbac, G.D.; Schnappauf, A.; Giannis, K.; Bertl, M.H.; Moritz, A.; Ulm, C. Guided autotransplantation of teeth: A novel method using virtually planned 3-dimensional templates. J. Endod. 2016, 42, 1844-1850. [CrossRef]

39. Juslin, J.; Jääsaari, P.; Teerijoki-Oksa, T.; Suominen, A.; Thorén, H. Survival of Autotransplanted teeth with open apices: A retrospective cohort study. J. Oral Maxillofac. Surg. 2020, 78, 902.e1-902.e9. [CrossRef]

40. Ashkenazi, M.; Shashua, D.; Kegen, S.; Nuni, E.; Duggal, M.; Shuster, A. Computerized three-dimensional design for accurate orienting and dimensioning artificial dental socket for tooth autotransplantation. Quintessence Int. 2018, 49, 663-671. [CrossRef]

41. Anitua, E.; Mendinueva-Urkia, M.; Galan-Bringas, S.; Murias-Freijo, A.; Alkhraisat, M.H. Tooth autotransplantation as a pillar for 3D regeneration of the alveolar process after severe traumatic injury: A case report. Dent. Traumatol. 2017, 33, 414-419. [CrossRef] [PubMed]

42. Gonzalez-Ocasio, J.; Stevens, M. Autotransplantation of third molars with platelet-rich plasma for immediate replacement of extracted non-restorable teeth: A case series. J. Oral Maxillofac. Surg. 2017, 75, 1833.e1-1833.e6. [CrossRef] [PubMed]

43. Mohd Mokhtar, S.; Abd Jalil, L.; Muhd Noor, N. Autotransplantation of ectopic permanent maxillary incisors. Case Rep. Dent. 2017, 2017, 7361924. [CrossRef] [PubMed]

44. Armstrong, L.; O'Reilly, C.; Ahmed, B. Autotransplantation of third molars: A literature review and preliminary protocols. Br. Dent. J. 2020, 228, 247-251. [CrossRef] 